\title{
CARAJICOMEDIA DE JUAN GOYTISOLO: ENTRE LA RISA ABIERTA Y LA IRONÍA SOTERRADA ${ }^{1}$
}

En sus trabajos sobre la obra de Juan Goytisolo, la crítica maneja con frecuencia el término de 'ironía'. La importancia de la ironía en la obra de Goytisolo se ha admitido sobre todo en relación con el Tríptico del mal ${ }^{2}$, una trilogía publicada por el autor entre 1966 y 1975, y respecto de las novelas que han aparecido inmediatamente después (Makbara (1980), Paisajes después de la batalla (1982)). Así, los críticos han analizado el tratamiento irónico del discurso del nacional-catolicismo en Don Julián (Epps 1996) ${ }^{3}$, la revisión irónica del realismo crítico en Juan sin tierra (Ambrozio 1987), y los juegos metaficcionales de tipo irónico en Paisajes después de la batalla (Pérez 1987). Sin embargo, se observa luego una evolución hacia un desinterés paulatino por la problemática de la ironía, que se debe en gran parte al énfasis en la influencia de la mística, de la espiritualidad y de la muerte en las novelas 'de madurez'. ${ }^{4}$ El presente trabajo quiere demostrar que la ironía sigue cumpliendo un papel esencial en una novela tardía del autor, titulada Carajicomedia, de Fray Bugeo Montesino y otros pájaros de vario plumaje y pluma (2000). Si bien es cierto que resulta llamativa la presencia de la burla, de la risa y de lo grotesco en el texto, se quiere argumentar a continuación que eso no impide que la ironía forme la estructura profunda del texto. Dicha ironía permite cuestionar sutilmente el autorretrato grotesco de Juan Goytisolo, igual que las muchas polémicas sobre la representación del árabe o de la homosexualidad en la obra del autor.

A primera vista, Carajicomedia, de Fray Bugeo Montesino y otros pájaros de vario plumaje y pluma se caracteriza por una vuelta hacia la sátira, la burla y la risa, conllevando una intención abiertamente crítica. En el siguiente comentario, el narrador del primer capítulo describe el proyecto literario de un cierto Juan que vive en la Rue Poissonière, exponiendo claramente el propósito de Carajicomedia:

Preparaba -o perpetraba- al parecer una novela -que el propio autor calificaba de armatoste, mamotreto o artefacto-, cuya realización le exigía muchas lecturas y años de trabajo. Una historia de la sexualidad a la luz de la doctrina católica por medio de un viaje por la lengua castellana desde la Edad Media hasta hoy. Quería transcribir sus experien- 
Con el propósito paródico, el narrador denomina pues el procedimiento que permite "poner al desnudo" la hipocresía del lenguaje eclesiástico, y sobre todo la del "autor del Kempis moderno". Con esta fórmula, se alude a uno de los intertextos principales de Carajicomedia: Camino (1939) de Escrivá de Balaguer, fundador del Opus Dei. ${ }^{5} \mathrm{Si}$ bien el empleo de un lenguaje alusivo en la novela -en ningún momento se menciona explícitamente ni el título de Camino, ni tampoco el nombre de su autor-podría llevarnos a calificar esa parodia de irónica, es cierto también que dichas alusiones indirectas al blanco (el Opus Dei) de la parodia son tan obvias que resulta más adecuado hablar aquí de una burla o de una sátira. ${ }^{6}$

La hipocresía del lenguaje opusdeístico es pues el blanco principal de la novela, hipocresía subrayada además por la reescritura de otro intertexto principal en la novela: la Carajicomedia procedente del Cancionero de burlas provocantes a la risa (1519). En este texto poco conocido y recuperado por Goytisolo, la burla atañe asimismo a la hipocresía del clero y a su relación ambigua con el sexo, sin conllevar por lo tanto la dimensión homoerótica presente en el texto goytisoliano.

La cita anterior refleja también el carácter autobiográfico de la novela: no por casualidad el nombre tanto como el domicilio del autor coinciden con los de Juan Goytisolo. ${ }^{7}$ Además, se añade que el autor de la novela quería describir sus "experiencias de ligón", lo cual es una referencia obvia a las aventuras homosexuales relatadas por Goytisolo en su segundo libro autobiográfico, En los reinos de taifa (1986). La alusión a la "libido textual" en el pasaje citado es un guiño irónico a la importancia de la (homo)sexualidad en ella, intensificada por la lectura en clave homosexual de Camino. ${ }^{8}$ Por otro lado, esta expresión recuerda la influencia que tuvieron los ensayos de Barthes y de Severo Sarduy sobre la dimensión placentera y erótica de la escritura en la poética de Goytisolo. ${ }^{9}$

El presente trabajo no analizará en detalle dicha burla de la iglesia y de su concepción de la sexualidad, tal como se traduce en la parodia de Camino, ni tampoco la intertextualidad que existe entre la novela de Goytisolo y la Carajicomedia del siglo XVI. Más bien, quisiera mostrar la relación compleja que surge por la presencia simultánea de una ironía metaficcional y la auto-ironía en la novela. Conviene recordar primero que no siempre es fácil establecer un límite tajante entre la metaficción y la ironía metaficcional. Si la autoreflexividad incluye un distanciamiento crítico con respecto a ciertas normas estéticas, en particular frente al principio mimético, no siempre es fácil determinar cuándo este distanciamiento es irónico y cuándo no lo es. El criterio para establecer la distinción consiste sin duda en el carácter implícito y lúdico de la ironía. 
Desde los primeros capítulos de Carajicomedia, las conversaciones entre el narrador Jaime Gil de Biedma y el Père de Trennes, un cura estrafalario del Opus Dei, permiten incluir comentarios sobre la novela que estamos leyendo. Así, el narrador y el Père evalúan el nuevo proyecto de su común amigo "Juan", quien según las palabras del Père está "cada vez más encerrado en sí mismo y en su escritura laberíntica", por lo cual los demás deben sufrir sus "altibajos de humor". (Goytisolo 2000: 20) Aparte de este tipo de alusiones auto-irónicas a la personalidad de "Juan", se resume en varias ocasiones el propósito de su nuevo proyecto novelesco, como en el pasaje siguiente que se abre con una pregunta del narrador:

“Es autobiografía o novela? ¿Hay un argumento, episodios, personajes reales?”
El argumento es lo de menos, argüía de prestado el père de Trennes. Lo que nuestro co-
mún amigo pretende es disponer el oído a la escucha de las voces del pasado para apro-
piarse de ellas y convertirse en dueño y señor de su escritura, olvidándose de quienes
bregan por serlo de la literatura y la vida literaria. La vitalidad de un artista se mediría
así por su aptitud para asimilarse las distintas corrientes literarias de la tradición en la
que se inscribe al servicio de un proyecto original, vasto y ambicioso [...]. El père de
Trennes dudaba no obstante de la viabilidad de la empresa, y yo también. Puestos a ele-
gir entre Forster y Bajtín, me quedo con Forster y sus razonables preceptos y pautas. Pe-
ro aguardaba la ocasión de discutir de ello con Juan. (Ibídem: 21 ; itálica del original)

La definición de la nueva empresa literaria de ese "Juan" (ibídem: 20) recuerda en muchos aspectos algunos ensayos de Juan Goytisolo. Son conocidos tanto su oposición al mercantilismo de los escritores, designados en otra ocasión por Günter Grass como "palomos amaestrados" dispuestos a servir el mercado editorial ${ }^{10}$, como su rechazo de la estética à la Forster. El modelo de Goytisolo lo constituye la novela cervantina, sinónimo de la revitalización, libertad creadora, inventiva lingüística, y parodia de los géneros caídos en desuso. Al adoptar estos mismos principios, la novela cervantina de hoy en día ya no se puede definir en oposición a un género como la novela pastoril o caballeresca, sino que tiene que buscar su equivalente actual. Según Goytisolo, el código literario que ahora se presta mejor a la parodia, es la estética realista, cuyo apego a un lenguaje acartonado y cuya escasa experimentación con las posibilidades del género novelesco son fustigados con frecuencia.

No obstante, la ironía del pasaje no se produce por la formulación de este proyecto novelesco en sí, sino por el distanciamiento de los personajes con respecto a él. El Père de Trennes se va a constituir a través de toda la novela como el doble pero también antagonista de su "discípulo barcelonés" (ibídem: 26), J.G., o simplemente Juan. Pero sus dudas acerca de la viabilidad del proyecto son secundarias, puesto que el lector se da cuenta muy pronto de que su inconformidad no trasciende mucho en el resultado final. Además, la inconsistencia tanto del Père como del narrador (identificable como Jaime Gil de Biedma) se pone de relieve cuando, algunos párrafos más adelante, el Père de Trennes anuncia de repente que ha abandonado su identidad anterior para convertirse en Fray Bugeo, el autor ficticio ${ }^{11}$ de la Carajicomedia del siglo XVI. Sobre este cambio repentino, afirma luego el narrador: "Los anacronismos del ex-père de Trennes y bisoño Fray Bugeo me encantaban. ¿Se había 
arrimado por fin, como yo aconsejaba a Juan, a la tradición literaria inglesa de Sterne y Swift?" (Goytisolo 2000: 21-22; itálica del original) El narrador (Gil de Biedma) da aquí un giro radical en comparación con su planteamiento anterior: su entusiasmo por la tradición literaria de Sterne (los anacronismos) y Swift (la sátira), es incompatible con su interés por Forster, demostrado en el pasaje extenso citado anteriormente.

Este tipo de rupturas de la ilusión mimética en el texto son continuas: el narrador con frecuencia se dirige directamente al lector ("cruel lector", ibídem: 22), o introduce comentarios sobre el propio texto. Así, el narrador del capítulo 9, 'En el café de los pájaros', elude un esfuerzo de descripción que él considera inútil en la siguiente frase: "Estaban sentados frente a frente en los sillones del tresillo ya descrito." (Ibídem: 197) Pero hay que darse cuenta que este tresillo no fue descrito en este mismo capítulo, sino en una de las primeras páginas de la novela (ibídem: 13), por lo cual el esfuerzo que debe hacer el lector para localizarla es considerable y se establece un contraste irónico con la pereza del narrador. Otro pasaje ilustrativo figura al final del cuarto capítulo, 'El manuscrito II: las secretas moradas', cuando el "editor" (ibídem: 95) interrumpe bruscamente el relato para añadir la nota siguiente:

¿Cómo se escribe un grito?, se preguntaba el autor del relato de la señora Lozana. No
halló la respuesta o, si dio con ella, no la transcribió: nos dejó in albis. Pero el grito
sonó y resonó: fue grabado. Su fuerza interrumpió la redacción del manuscrito que el
lector trae entre manos. En una conversación con el abate Marchena, incluida en el ca-
pitulo quinto de este libro, Fray Bugeo identifica con malicia a su autor. (Ibídem: 94-
95; itálica del original)

De nuevo se observa una ruptura de la ilusión mimética mediante una referencia a la materialidad de la escritura ("el manuscrito que el lector trae entre manos"). Además, se vuelve a exhibir también la estructura misma del texto: el editor conoce el desarrollo ulterior de la novela, y adopta una actitud superior con respecto a Fray Bugeo (la reencarnación pues del Père de Trennes) al evaluar su intervención en el texto ("con malicia"). En la primera frase de la cita, llama la atención la alusión al "autor del relato de la señora Lozana", con quien se designa no sólo a Francisco Delicado, el autor del Retrato de la lozana andaluza (1528) sino indirectamente también al propio Fray Bugeo, el narrador en primera persona de este capítulo. En este contexto, cabe recordar que la Lozana es considerada por el propio Goytisolo como uno de los primeros libros que integran una reflexión metaficcional sobre el estatuto del autor, y que la misma obra inspiró a Cervantes en su juego de desautorización en el Quijote. Es preciso detenerse pues en el significado de la frase en cuestión: el grito no pudo ser transcrito, a pesar de las reflexiones del autor del Retrato (en principio, Delicado), pero sí pudo ser grabado. A través de esta alusión implícita al 'presente eterno' que caracteriza el proceso de la intertextuali$\operatorname{dad}^{12}$, el texto se burla del principio de verosimilitud convirtiéndose en un espacio atemporal en el que convergen el autor medieval de la Lozana y los métodos de la grabación sonora. 
Al mencionar la malicia de Fray Bugeo con respecto a la identificación posterior del autor del grito, el editor refiere a la rivalidad permanente entre el fraile y su 'alter ego', el discípulo barcelonés o 'Juan Goytisolo'. De hecho, la última frase de la narración interrumpida ya insinúa quién es el desprestigiado autor del grito: "Podría referir incontables episodios ejemplares de sus sermones públicos y actos devotos y contemplativos de no haber metido el San Juan de Barbès su larga nariz en el tema $y$, con la desfachatez que le caracteriza..." (Goytisolo 2000: 94) Para entender esta enemistad entre Fray Bugeo y San Juan de Barbès conviene situarla en su contexto. En el tercer capítulo, 'Introito a destiempo', Fray Bugeo comenta sus impresiones sobre sus salidas nocturnas con Gil de Biedma y compañía en el primer capítulo (ibídem: 1417), cuando todavía era el Père de Trennes. El narrador es ahora Fray Bugeo mismo:

El poeta [Jaime Gil de Biedma], tras comprobar mi sequedad y desarrimo al laboreo de las zonas en que él acendraba sus naturales dones de santo, me aconsejó que siguiera el ejemplo de su colega escritor Juan Goytisolo, cuya predicación con el ejemplo le había enhestado, según el rumor público, a las cimas de la perfección. Aunque luego lamenté su fisgoneo y tendencia a apropiarse a libro abierto de algunos capítulos de mi dietario, aprendí mucho de los dichos y hechos de su misión. Él me guió a las capillas en donde encontré a mis catecúmenos más fervientes y creo que merece ser proclamado, como propuso Severo Sarduy a petición de las Hermanas del Perpetuo Socorro, San Juan de Barbès-Rochechouart. (Ibídem: 71-72)

Fray Bugeo explica aquí cómo empezó a seguir el ejemplo de Juan Goytisolo, cuyo nombre de santo le fue efectivamente otorgado por Severo Sarduy. ${ }^{13}$

Cabe fijarse en esta crítica del narrador respecto del fisgoneo de su colega. Con "mi dietario", Fray Bugeo se refiere a la Carajicomedia original. La denuncia de Fray Bugeo acerca de la apropiación indebida que efectúa Juan Goytisolo de su dietario es un ejemplo excelente de la ironía metaficcional. Supuestamente, el autor de los dos manuscritos dedicados a las experiencias santas son de la mano de Fray Bugeo/el Père de Trennes. Estos mismos manuscritos mantienen una relación intertextual predilecta con dos textos. Primero, con la Carajicomedia original de Fray Bugeo, que en este sentido se estaría reescribiendo a sí mismo. Segundo, con el último tomo de la autobiografía de Juan Goytisolo, a la cual alude en varias ocasiones. De hecho, Fray Bugeo afirma haber compartido varios "santos" con Juan Goytisolo y se refiere a En los reinos de taifa para que el lector compruebe que algunos personajes son los mismos. Con respecto a "Mohamed" (ibídem: 27), por ejemplo, Fray Bugeo dice lo siguiente: "Le conocí en Barbès en abril de 1963: es el personaje descrito en el capítulo V de En los reinos de taifa, obra de mi amigo y discípulo barcelonés, padrastro y no padre de su autobiografía novelada, compuesta con retazos de mis diarios y glosas a pie de página." (Ibídem: 27)

Está claro que entre Fray Bugeo y su "amigo" se establece una rivalidad cada vez mayor. El primero expresa su irritación cuando apunta que en su visita a la alhama se había topado con el "inevitable San Juan de Barbès- 
Rochechouart” (Goytisolo 2000: 64). También la frase citada sobre la desfachatez de San Juan quien mete "su larga nariz" en asuntos ajenos subraya esta rivalidad. Al final de la conversación con el abate Marchena en el capítulo 7, el Père de Trennes vuelve a identificar al autor del grito: "Además, el San Juan de Barbès no podía aguantar que yo, su discípulo, le aventajara en su propio terreno. Pegó un grito y tuve que suspender la narración." (Ibídem: 173) Dicho de otra manera, "San Juan de Bargés", alias Juan Goytisolo se puso celoso por el éxito que tenía su doble ficticio el Père de Trennes/Fray Bugeo entre sus propios santos y suspendió el segundo manuscrito por medio de un grito. Hacia el final de la novela, en los capítulos 9 y 10, el narrador es aquel San Juan de Barbès y muestra a las claras su irritación ante la persecución que sufre por parte de su "doble" (ibídem: 196), sobre quien se pregunta si no se trata de "un retrato grotesco y cruel de mí mismo". (Ibídem: 198) Con el objetivo de "aclarar de una vez para siempre quién había copiado a quién, quién era el aprovechón, quién el plagiado", el barcelonés decide finalmente invitar a Fray Bugeo a resolver la cuestión con él ante sus amigos, propuesta que desemboca finalmente en otro debate televisivo en el que San Juan repitiendo la experiencia del narrador en La saga de los Marx- deja una pésima impresión. En resumen, se observa un desdoblamiento bastante grotesco del autor ${ }^{14}$, que se extiende en una fragmentación múltiple con unos límites borrosos.

Después de comentar esa ironía metaficcional, relativa a las normas estéticas mismas, conviene examinar en detalle la representación auto(r)-irónica del autor maurófilo "San Juan de Barbés". En una entrevista con Rosa Mora, Goytisolo afirmó que quiso parodiar Camino de Balaguer en Carajicomedia, "y al mismo tiempo convertirla en una autobiografía paródica". (Ibídem: 8) Para el análisis de la auto-ironía en esta novela, es preciso recordar primero el argumento que Alison Ribeiro de Menezes elabora al respecto en su artículo 'The Mystical and the Burlesque: The Portrayal of Homosexuality' (2002). Desde su punto de vista, Carajicomedia de Goytisolo reúne dos tendencias diferentes. Por un lado, incluye un regreso hacia la estética de oposición que estaba al origen de las novelas de la trilogía, esta vez mediante la parodia de Camino de Balaguer. Por otro lado, dicha estética de oposición es matizada por una estética de la ambigüedad, dado que Goytisolo no sólo subraya la soterrada dimensión sexual en Camino, sino que recurre también al lenguaje místico para hablar de la sexualidad. En este sentido, Carajicomedia se inscribe en la misma línea que Virtudes del pájaro solitario (1988), en la que se exploraban los límites de la ambigüedad en el discurso místico. Ribeiro de Menezes indica al respecto que la palabra "pájaro" que figura en el título completo, Carajicomedia de Fray Bugeo Montesino y otros pájaros de vario plumaje y pluma, ya se utilizaba en su doble significado en Las virtudes del pájaro solitario. De hecho, el término 'pájaro' es masculino desde un punto de vista gramatical, pero femenino según la concepción mística de un poeta como San Juan de la Cruz, al referir al 'alma', a la 'novia' en busca de Dios. Esto muestra que el concepto de género ya no se concibe desde una perspec- 
tiva binaria, de oposición, sino que se insiste en su carácter ambiguo. Es cierto que en Carajicomedia los santos del escritor no incluyen exclusivamente a gayanes que corresponden a la concepción viril y soterrada de la sexualidad en Camino, sino también a pájaros como las "Hermanas del Perpetuo Socorro" (Goytisolo 2000: 77; una referencia a Auxilio y Socorro de Sarduy) o al travestido "M.P.". (Ibídem: 108; una alusión a Manuel Puig) En este sentido, la noción de género en Carajicomedia es mucho más amplia que en Don Julián, por ejemplo.

Ribeiro apunta asimismo a la importancia de la intertextualidad con el segundo tomo autobiográfico de Goytisolo, En los reinos de taifa (1986):

\begin{abstract}
Goytisolo's latest novel is thus a re-evaluation of his previous textual/sexual practice and an illustration, from a personal perspective, of discourse simultaneously as power and as resistance. It is also, as the autobiographical intertext demonstrates, a reflection on the textual presentation of homosexuality. Two discursive strategies achieve this: the use of a polyvalent discourse which contains both repression and resistance, as outlined above; and a form of autobiographical intertextuality which allows for an element of self-questioning. (Ribeiro 2002: 110)

[La última novela de Goytisolo es pues una re-evaluación de su práctica textual/sexual anterior y una ilustración, desde una perspectiva personal, del discurso a la vez como poder y como resistencia. Al mismo tiempo es también -como lo demuestra el intertexto autobiográfico- una reflexión sobre la presentación textual de la homosexualidad. Dos estrategias discursivas llevan a ello: el uso de un discurso polivalente conteniendo tanto la represión como la resistencia, tal como se destacó anteriormente; además de una forma de intertextualidad autobiográfica que da lugar también a un elemento de autocuestionamiento.]
\end{abstract}

Con la referencia al empleo de un discurso polivalente que combina el poder y la resistencia dentro de la novela, Ribeiro de Menezes se refiere a la debilitación de la estética de la oposición (la parodia de Camino) a favor de la estética de la ambigüedad (su entretejimiento con un lenguaje místico). Sin embargo, no hay motivo por el cual suponer que en Carajicomedia Goytisolo cuestiona su propia representación de la homosexualidad (según la estética de la oposición) en sus autobiografías, dejando intacta su exploración del lenguaje místico (según la estética de la ambigüedad). Dicha interpretación es sintomática de la tendencia de otros críticos (como Escudero 1994) a subrayar la dimensión mística en la obra tardía de Goytisolo. Al contrario, la omnipresencia de una auto-ironía en la novela - poco entrevista por estos mismos críticos $^{15}$ - lleva precisamente a un cuestionamiento de ambas estéticas.

Esto lo afirma también Ribeiro de Menezes -aunque de modo indirectocuando advierte que Goytisolo pone en práctica cierto "humour against himself". (Ibídem: 111) [humor contra sí mismo] Esta auto-ironía -antes que "humor"- se instaura básicamente mediante la relación intertextual entre Carajicomedia y el segundo tomo autobiográfico del autor. No hay que ser ningún "attentive reader" [lector atento] (ibídem: 110) para darse cuenta de dicha intertextualidad: aparte de las múltiples pistas implícitas, el narrador de 'Mis santos y sus obras' (el fray Bugeo alias Père de Trennes) menciona incluso literalmente el título de En los reinos de taifa para indicar que la descripción de un amante suyo está inspirada en aquel libro autobiográfico de 
1986. Más en particular, se observan coincidencias en los episodios sobre Mohamed, Buselham y Lajdar. El elemento más importante es que se trata de tres casos en los que el encuentro sexual resulta especialmente violento. La relación sexual que mantiene fray Bugeo con estos 'santos', algunos -como Buselham- sujetos "a ramalazos incontrolables de violencia" (Goytisolo 2000: 31), reproduce por lo tanto el deseo hipermasculino, la insistencia en la virilidad, la violencia, y la tendencia al sadomasoquismo.

En su análisis de esta intertextualidad, Ribeiro de Menezes indica que la descripción de los santos no puede sino recordar la crítica de Epps y Smith acerca de la representación problemática de la homosexualidad en la prosa de Goytisolo. (Ribeiro 2002: 111) Sus reparos fueron principalmente dos. Primero, su idealización del físico del hombre magrebí implicaba una perspectiva orientalista poco aceptable en estos tiempos poscoloniales. Crítica tanto más justificable si se tiene en cuenta el interés de Goytisolo por la teoría poscolonial y su conocimiento de la obra de críticos como Edward Said, Hichem Djaït y otros. En segundo lugar, se le reprochaba a Goytisolo su concepción violenta de la sexualidad: no sólo Paul Julian Smith, sino también Brad Epps se ha distanciado de la representación parcial que hace Goytisolo de la homosexualidad. Sólo caben en su mundo los machos fuertes, viriles, el sexo duro y violento, y se percibe una tendencia a burlarse de los gays más afeminados.

Según Ribeiro de Menezes, Goytisolo acaba por distanciarse en Carajicomedia de su propia representación de la homosexualidad tal como figuraba en esta autobiografía. A este respecto, Ribeiro observa por un lado que "[i]n Goytisolo's favour one might note that he admits to this sado-masochistic view of pleasure". (Ibídem) [a favor de Goytisolo se podría notar que él reconoce esta perspectiva sado-masoquista del placer] Este comentario ilustra la tendencia entre los goytisolianistas a centrar la discusión literaria en unos argumentos a favor o en contra de la actitud personal o (in)moral del autor. Pero también añade Ribeiro que Carajicomedia cuestiona "the initial depiction of homosexual sex as violent and as an exchange between sexual and intellectual domination". (Ibídem) [la presentación inicial del sexo homosexual como violento y como un intercambio entre dominación sexual e intelectual] El uso de términos místicos para describir a sus santos, contribuye desde el punto de vista de Ribeiro a relativizar la violencia semiótica presente en el discurso autobiográfico. Es así como ella llega a la conclusión siguiente:

The discursive instability thus established suggests that Goytisolo aims to move beyond an oppositional aesthetic, setting up a series of intertextual echoes which hover between the parodic and the ecstatic, the burlesque and the mystical, without either of them achieving total dominance. (Ibídem: 112)

[La inestabilidad discursiva así establecida sugiere que Goytisolo se propone ir más allá de la estética de oposición, estableciendo una serie de ecos intertextuales que planean entre lo paródico y lo extático, lo burlesco y lo místico, sin que ninguno de ellos adquiera el dominio total.]

Sin embargo, la adopción del lenguaje místico en ningún momento adquiere una dimensión seria en la novela, ni va en contra de su dimensión burlesca. 
De hecho, la novela no planea -como sostiene Ribeiro- entre la parodia y el éxtasis, ni entre lo burlesco y lo místico, sino que la adopción del discurso místico refuerza la burla y la ironía, y les es claramente subordinado. Ni siquiera cabe descartar que la integración del lenguaje místico forme una faceta más de la auto-ironía del autor, que no sólo ridiculizaría así su propia predilección por el sexo violento con árabes, expuesta en En los reinos de taifa, sino también la tendencia hacia el misticismo desarrollada en Virtudes del pájaro solitario o La cuarentena. De todos modos, el lenguaje místico utilizado en Carajicomedia es ante todo una jerga que en ningún caso tiene el mismo alcance poético que en aquellas novelas anteriores. Por eso mismo tal vez sea más acertado decir que no se parodia tanto la dimensión poética de la mística tal como figura en la obra anterior del propio autor, como el misticismo bastante más tosco del propio Escrivá de Balaguer.

La auto-ironía no implica pues necesariamente un 'mea culpa' retrospectivo tal como sugiere Ribeiro. De hecho, no se puede perder de vista la función suspensiva de la ironía: 'Mis santos y sus obras' y 'Las secretas moradas' se pueden leer como un desafío abierto planteado por Goytisolo a la crítica que le ha reprochado la representación hipermasculina de la homosexualidad, y su idealización problemática del Oriente. La manera provocadora en la que Goytisolo vuelve a repetir estos estereotipos, mediante un diario semiautobiográfico, sugiere a primera vista que son los críticos los que constituyen el blanco privilegiado de la ironía. La dimensión auto(r-re)afirmativa de la auto(r)-ironía prevalece aquí por lo tanto a su dimensión auto-crítica.

Esta impresión queda confirmada en el capítulo ocho, 'Consejos y varapalos al Père de Trennes'. En el primer apartado, el Père de Trennes se deja aconsejar por la "autorizada opinión del Maurólogo, del Santo de Barbès". (Goytisolo 2000: 179) Éste empieza a imitar el discurso de un "profesor de Oxford", sin duda una referencia a Paul Julian Smith ${ }^{16}$, que le pide cuentas sobre la representación de la homosexualidad en sus novelas:

Su representación de la homosexualidad me parece cuando menos equívoca: adolece de pasividad y masoquismo, raya en la complicidad con los poderes de dominación ancestrales. Como su amigo Genet, ensalza poéticamente a los matones del hampa y guardaespaldas rudos. Es usted, o dice ser, un demócrata convencido, pero su obra literaria se alimenta de la contradicción y ambivalencia. Sus personajes carecen de la conciencia y del orgullo del militante de hoy, no transmiten al lector gay opciones políticas radicales ni le incitan a defender sus derechos: matrimonio, ley de parejas, ingreso en el ejército... En suma, dispara pólvora en salvas pues presenta la alienación de forma irremediablemente alienada. (Ibídem: 178-179)

El pastiche del discurso de la 'queer theory' se observa primero en el estilo académico: el uso de términos típicos de la crítica literaria ("equívoco", "ambivalencia"), el uso de un registro escrito elevado ("adolece de", "se alimenta de"), y en particular la afición a las construcciones retorcidas, con una predilección por la acumulación de adverbios ("presenta la alienación de forma irremediablemente alienada"). Además, Goytisolo se vuelve a burlar de 
la exigencia de una lucha activa a favor de los derechos de los 'gays' en sus novelas. ${ }^{17}$ En particular, el derecho a ingresar en el ejército resulta totalmente incompatible con el anti-militarismo de Goytisolo. La ironía suprema de este párrafo consiste en que es San Juan el que le está aconsejando aquí al Père de Trennes, es decir, después de tantas críticas Goytisolo sugiere irónicamente que su propia opinión sobre estos asuntos de la crítica es la más 'autorizada'.

En suma, la perspectiva auto(r)-irónica en Carajicomedia sobre la homosexualidad ilustra la dificultad de fijar la interpretación de la ironía ${ }^{18}$, reforzada por el carácter poco fidedigno de los narradores. ${ }^{19}$ La insistencia de Linda Hutcheon sobre el carácter transideológico de la ironía resulta aquí especialmente pertinente: la ironía puede servir fines ideológicos muy diferentes, dependiendo de la interpretación que le dé el destinatario/el lector. Si Alison Ribeiro de Menezes interpreta la auto-ironía como una revisión de Goytisolo de su postura anterior, también se puede considerar al contrario como una reafirmación de su posición inicial y como un desafío a la crítica. Finalmente es el lector quien decide cuál es la interpretación que prefiere: la posición real y auténtica del autor es imposible de restablecer a base del texto, y además largamente superada por su complejo juego enunciativo que impide limitar la interpretación a la intención explícita de su autor.

Pero esto implica también que la burla del Opus Dei en Carajicomedia se ve afectada por la auto-ironía, y que su crítica mordaz resulta hasta cierto punto amortiguada: por mucho que la hipocresía de la concepción eclesiástica es criticada, también se destacan los problemas en la representación goytisoliana de la homosexualidad. E incluso surge la pregunta si lo esencial de una novela no es más bien la reflexión sobre este problema mismo de la representación. Desde esta perspectiva, las novelas tardías de Goytisolo denuncian el absolutismo de cualquier ideología, limitándose a reflejar-como si se tratara de un observador ajeno- todas estas disputas ideológicas. Tal neutralidad ideológica es por supuesto falaz, y lo muestra la presencia de la misma parodia del lenguaje eclesiástico que es un aspecto esencial de la novela.

La auto-ironía conlleva así un distanciamiento del autor con respecto a la crítica que cuestiona la representación de la homosexualidad en su obra, lo cual significa también que Goytisolo se desresponsabiliza en cierto sentido de las implicaciones ideológicas de sus textos literarios. Sin embargo, esta 'desautorización' se ve simultáneamente ironizada por la omnipresencia de aquel personaje de "San Juan de Barbés" (Goytisolo 2000: 94) en el texto. Al inmiscuirse continuamente en el relato y en el debate sobre la representación de la homosexualidad en su novela, demuestra precisamente que el autor no ha muerto y que el debate le sigue interesando a pesar de todo. Pero dicha 'presencia' del autor en su texto es ironizada a su vez también dado que el carácter poco fiable y grotesco de este personaje imposibilita al mismo tiempo su identificación ingenua con el propio autor. En resumen, los juegos complejos de la ironía en este texto dificultan una lectura enfocada exclusivamente en la estética de la oposición -la burla y la risa abiertas- del texto, invitándonos precisamente a que el viaje por la lengua castellana desde la 

tura con las que cualquier autor -desde Francisco Delicado hasta Juan Goytisolo- se ha topado.

1. Para una versión más extensa de este análisis, se puede consultar La poética de la ironía en la obra tardia de Juan Goytisolo (1993-2000). (Adriaensen 2006, en prensa)

2. Este título se otorgó posteriormente a la trilogía, en una nueva edición que sacó recientemente la editorial El Aleph (2004).

3. El título original de esta novela era Reivindicación del conde don Julián, pero fue abreviado en la última edición de Cátedra (2004).

4. Véanse en particular Eros, mística y muerte en Juan Goytisolo (1982-1992), (EscuderoRodríguez 1994) y 'Apocalipsis y ecologismo, muerte y posteridad: de Paisajes después de la batalla a La saga de los Marx de Juan Goytisolo'. (Cibreiro 2001)

5. La gran popularidad de Camino explica su comparación con el Kempis, es decir, la Imitación de Cristo (1472) de Tomás de Kempis, igual que el hecho de que ambos autores fueron canonizados por la iglesia. De hecho, el Papa Juan Pablo II canonizó a Escrivá de Balaguer el día 6 de octubre de 2002 .

6. Es lo que hace Goytisolo en una entrevista con Wolfgang Eilenberger, donde el autor utiliza la palabra 'ironía' para caracterizar su novela Las semanas del jardín, añadiendo lo siguiente sobre Carajicomedia: "Mi tendencia actual apunta a ello [a la ironía], y también a la sátira de determinados lenguajes, como el de la iglesia con respecto al sexo en Carajicomedia." (Eilenberger 2003: 26).

7. La referencia a la Rue Poissonière es frecuente en las novelas de Juan Goytisolo. En el tomo autobiográfico En los reinos de Taifa el autor comenta su relación afectiva con esta casa parisina en la que vivió muchos años con su pareja Monique Lange.

8. En su ensayo 'La libido textual de Camino', Goytisolo destaca asimismo la 'libido textual' del libro de Balaguer. (Goytisolo 2001: 133)

9. Sobre todo Severo Sarduy ha influido mucho en esta concepción erótica que tiene Goytisolo de la escritura. Véase al respecto su ensayo 'El lenguaje del cuerpo', en Disidencias (1992: 227-228). La expresión misma de "libido textual" es una referencia obvia al ensayo de Roland Barthes, Le plaisir du texte (1973).

10. Goytisolo se extiende sobre esta distinción de Grass entre los "pájaros que ensucian su propio nido", los escritores dispuestos a tomar riesgos en el plano estético e ideológico, y los "palomos amaestrados" en el epílogo de su ensayo de volúmenes Pájaro que ensucia su propio nido (2001).

11. Aunque los críticos coinciden en considerar la Carajicomedia del Cancionero como una obra anónima, en el texto mismo la autoría se atribuye a un personaje ficticio llamado Fray Bugeo Montesino.

12. La noción del 'presente eterno' se encuentra a la base de la concepción que tiene Juan Goytisolo de la intertextualidad. En el epílogo de Pájaro que ensucia su propio nido, Goytisolo reproduce la siguiente cita de Bajtín para explicar esa noción de 'atemporalidad': "Una obra no puede vivir en los siglos venideros si no se alimenta de los siglos pasados. Si hubiera nacido exclusivamente en el ahora, si no prolongara el pasado y no se hallara ligada de modo consubstancial a éste, no podría vivir en el futuro. Cuanto pertenece tan sólo al presente muere con él." (Goytisolo 2001: 407)

13. Goytisolo lo confirma en la entrevista con Rosa Mora: "Juan Goytisolo: "He escrito Carajicomedia riéndome yo solo y deseando que el lector comparta mi risa."” (Goytisolo 2000: 8)

14. En este sentido, Carajicomedia se puede considerar como la continuación de Paisajes después de la batalla, una novela que fue denominada por el propio autor como una "autobiografía grotesca". (Pereda 1982)

15. Javier Escudero no habla en ningún momento de la ironía, de la parodia o del humor en su libro. Se centra exclusivamente en temas como el lenguaje místico, la muerte y el Eros en la 
obra de Goytisolo. Un Eros que en ningún momento es asociado por el crítico con la subversión y la risa que se encuentra en Carajicomedia.

16. Véase la observación al respecto de Gould Levine 2001: 81. También es posible que el personaje sea una referencia a Brad Epps, quien publicó su libro Significant Violence (1996) en Oxford University Press. El propio Smith trabaja para la Universidad de Cambridge, pero el pasaje citado recuerda efectivamente más sus críticas que las de Epps.

17. La crítica de la política identitaria es especialmente patente en el cuarto apartado del quinto capítulo ('Consejos y varapalos al Père de Trennes') en Carajicomedia.

18. Ya se indicó anteriormente que la presencia de travestidos y de transexuales en la novela matiza además la presencia exclusiva de la homosexualidad hipermasculina en la novela.

19. Pienso especialmente en la posición ambigua del narrador de inspiración autobiográfica con respecto a las exigencias de Ms Lewin-Strauss. En general, los 'mea culpa' no parecen fidedignos, tal como lo observa también Gould Levine (2001: 83). La confusión que crea este narrador se desprende del mero hecho de que Ribeiro de Menezes sí interprete estos "mea culpa' en Carajicomedia como "sinceros".

\section{BIBLIOGRAFÍA}

Adriaensen, B.

2006 La poética de la ironía en la obra tardía de Juan Goytisolo (1993-2000). Madrid:

(en prensa) Verbum.

Ambrozio, L.

1987 'Juan sin Tierra de Juan Goytisolo: Ironia e Paródia: Criação.' En: Revista Letras (Curibita, Paraná, Brasil) 36: 117-131.

Anónimo

1841 Cancionero de obras de burlas provocantes a la risa. Con advertencias de Luis de Usoz y Río. [1519] Madrid, Luis Sánchez, (U/1932).

Cibreiro, E.

2001 'Apocalipsis y ecologismo, muerte y posteridad: de Paisajes después de la batalla a La saga de los Marx de Juan Goytisolo.' En: Anales de la literatura española contemporánea XXVI, 2: 29-60.

Eilenberger, W. et alii

1998 'Nacionalidad cervantina. Una entrevista con Juan Goytisolo.' En: Espéculo 11 $<$ http://www.ucm.es/info/especulo/numero 11/jgoytiso.html >: 7 .

Epps, B.

1996 Significant Violence: Oppression and Resistance in the Narratives of Juan Goytisolo, 1970-1990. Oxford: Clarendon.

Escrivá de Balaguer, J.M.

2001 Camino. [1939] Madrid: Rialp.

Escudero-Rodríguez, J.

1994 Eros, mística y muerte en Juan Goytisolo (1982-1992). Almería: Instituto de Estudios Almerienses.

Gould Levine, L.

2001 'De San Juan a Sor Juana: controversias feministas en la obra de Juan Goytisolo.' En: VV. AA. Encuentro con Juan Goytisolo. Imprévue 1-2, CERS-Université Paul Valéry de Montpellier III: 79-96.

Goytisolo, J.

1998 En los reinos de taifa. Madrid: Alianza, [1986].

2000 Carajicomedia, de Fray Bugeo Montesino y otros pájaros de vario plumaje y pluma. Barcelona: Seix Barral.

2001 Pájaro que ensucia su propio nido. Artículos y ensayos. Barcelona: Galaxia Gutenberg/Círculo de Lectores.

2004 Tríptico del mal. Barcelona: El Aleph.

Hutcheon, L.

1994 Irony's Edge. The Theory and Politics of Irony. Londres/Nueva York: Routledge. 
Mora, R.

2000 'Juan Goytisolo: 'He escrito Carajicomedia riéndome yo solo y deseando que el lector comparta mi risa', En: El País: Babelia, 19 de febrero: 8-9.

Pereda, R.

1982 'Juan Goytisolo: "Paisajes después de la batalla es mi primera novela de humor".' En: El País, 16 de noviembre.

\section{Pérez, Genaro J.}

1987 'Construcción y destrucción en Paisajes después de la batalla.' En: Ínsula 484: 7.

Ribeiro de Menezes, A.

2004 'The Mystical and the Burlesque: The Portrayal of Homosexuality.' En: Romance Studies 20, 2: 105-114.

Smith, P. J.

1992 'Homosexual Desire in Goytisolo's Trilogy of Treason.' En: Laws of Desire. Questions of Homosexuality in Spanish Writing and Film 1960-1990. Oxford: Clarendon Press: 55-90. 